\title{
Status and New Developments in Indoor Thermal Environmental Standards
}

\author{
B. W. Olesen, ${ }^{1)}$ Richard de Dear, ${ }^{2)}$ and Gail Schiller Brager ${ }^{3)}$ \\ ${ }^{1)}$ Wirsbo-Velta" GmbH \& Co. KG, Norderstedt/Germany \\ ${ }^{2)}$ Division of Environmental and Life Sciences, Macquarie University, \\ Sydney Australia \\ ${ }^{3)}$ Center for the Built Environment, University of California, \\ Berkeley USA
}

(received on April 19, 2001; accepted on Aug. 19, 2001)

\begin{abstract}
New concepts for standards on the indoor thermal environment are being proposed on the international level, with ISO (International Standard Organisation) and CEN (European Standard Organisation), and on the national level with ASHRAE (American Society of Heating, Refrigerating and Air Conditioning Engineers). Among the new developments are recommendations for acceptable thermal environments to be specified as classes. This allows for differences in national requirements and for buildings designs to have different quality levels. This will require, and encourage better dialog between the client (builder, owner) and the designer. There is also an ongoing discussion within the standards review committees about how people can adapt to higher indoor temperatures during summer in naturally ventilated (free running) buildings. A method for a whole year evaluation of the indoor thermal environment is also proposed.

The standards will be based on requirements for general thermal comfort (PMV, Operative temperature) and local thermal discomforts (radiant temperature asymmetry, draught, vertical air temperature differences, floor surface temperatures). One critical issue is the effect of air velocity. On one hand, increased air velocity has a beneficial effect at warm temperatures, but, on the other hand, increased air velocity may result in draught sensation in cooler temperatures. Another issue is the extent to which requirements of humidity need to be included in a standard for thermal comfort. Several recent research projects dealing with adaptation, influence of air velocity and the effect of humidity have been the basis for increasing the usefulness and accuracy of the standards.
\end{abstract}

Key words: indoor climate, thermal comfort, local discomfort, standards, PMV, adaptation, draught

\section{Introduction}

The main purpose of most heating and air conditioning system installations is to provide an environment that is acceptable to, and impairs neither the health nor performance of, the occupant. Knowledge of thermal climatic parameters, their influence on the occupants, and the influence of buildings and systems on these parameters, are relatively well documented in international standards. To be able to evaluate thermal comfort, the criteria for the relevant thermal parameters must be known together with the methods for their prediction (design stage), or measurement (commissioning and operation stage). There is also a need during development to test and evaluate the impact of new products on thermal comfort. International standards should make it easier for designers and industry, who work internationally, to use the same method. Of course national standards may better be applied exactly to the local weather conditions, type of buildings and user profiles.

This paper presents some of the methods and criteria that are present in existing international standards, or in standards that are currently being developed. Issues such as air velocity, adaptation, humidity and the yearly performance of buildings, are also discussed.

\section{Criteria for Thermal Comfort}

The environmental parameters that constitute the thermal environment are: temperature (air, radiant, surface), humidity and air velocity. The relevant personal parameters are clothing and activity level. Criteria for an acceptable thermal climate are specified as requirements for general thermal comfort [PMVPPD or operative temperature (air- and mean radiant 
temperature), air velocity, humidity] and local thermal discomfort [draught (mean air velocity, turbulence intensity, air temperature) vertical air temperature differences, radiant temperature asymmetry, surface temperature of the floor]. Such requirements can be found in existing standards and guidelines like EN ISO 7730 (1994), CR 1752 (1998) and ASHRAE 5592 (1992).

For most thermal parameters it has been possible to establish psychophysical relationships between the intensity of the parameter and a predicted percentage of people finding the conditions unacceptable. People may be dissatisfied due to general thermal comfort (PMV, operative temperature) and/or dissatisfied due to local thermal discomfort parameters (draught, radiant asymmetry etc.). At the present time there is no method for combining the percentages of dissatisfied people to give an accurate prediction of the total number of people finding the environment unacceptable. For example, we don't know if the dissatisfaction resulting from general thermal discomfort is additive with the percentages of those who are dissatisfied due to local discomforts, or whether the total dissatisfied may be less than the sum of the individual percentages (i.e. some people complaining about more than one particular problem simultaneously). Thus to simplify the situation, in ASHRAE Standard 55 the approach has been to specify criteria corresponding to $10 \%$ dissatisfaction with general thermal comfort, to which a net increase of another $10 \%$ dissatisfied due to local discomforts has been added, bringing the total level of thermal acceptability down to $80 \%$.

In real buildings, if may be desirable to establish different target levels of thermal dissatisfaction based on what is technically possible, what is economically viable, energy considerations, environmental pollution, or occupant performance. Therefore, it is suggested in the revision of ISO EN 7730 and ASHRAE-55 to specify different levels of acceptability like in CR 1752. Individual countries or contracts between client and designer can then specify which levels to be used. Table 1 gives recommended levels of acceptance for three classes of environment (CR 1752, 1998).

\subsection{General thermal comfort-Operative tempera- ture}

For general thermal comfort, Table 2 lists the criteria for operative temperature and air velocity corre-

Table 1. Three categories of thermal environment. Percentage of dissatisfied due to general comfort and local discomfort (CR 1752, 1998).

\begin{tabular}{|c|c|c|c|c|c|c|}
\hline Category & \multicolumn{2}{|c|}{$\begin{array}{c}\text { Thermal state of the } \\
\text { body as a whole }\end{array}$} & \multicolumn{4}{|c|}{ Local Thermal Discomfort } \\
\hline & PPD & $\begin{array}{c}\text { Predicted } \\
\text { Mean Vote }\end{array}$ & $\begin{array}{c}\text { Draught } \\
\text { Rate, DR }\end{array}$ & $\begin{array}{c}\text { Vertical } \\
\text { Air Temp. } \\
\text { difference } \\
\%\end{array}$ & $\begin{array}{c}\text { Warm or } \\
\text { Cool } \\
\text { Floor } \\
\%\end{array}$ & $\begin{array}{c}\text { Temperature } \\
\text { Asymmetry } \\
\%\end{array}$ \\
\hline A & $<6$ & $-0.2<$ PMV <+0.2 & $<15$ & $<3$ & $<10$ & $<5$ \\
\hline B & $<10$ & $-0.5<$ PMV $<+0.5$ & $<20$ & $<5$ & $<10$ & $<5$ \\
\hline C & $<15$ & $-0.7<$ PMV $<+0.7$ & $<25$ & $<10$ & $<15$ & $<10$ \\
\hline
\end{tabular}

Table 2. Example criteria for operative temperature and mean air velocity for typical spaces. Values assume $40 \% \mathrm{RH}$ in the winter, and $60 \%$ in the summer.

\begin{tabular}{|c|c|c|c|c|c|c|c|c|}
\hline $\begin{array}{c}\text { Type of } \\
\text { Building/ } \\
\text { Space }\end{array}$ & \begin{tabular}{|} 
Cloth \\
Cooling \\
Season \\
(summer) \\
clo
\end{tabular} & $\begin{array}{l}\text { ing } \\
\text { Heating } \\
\text { Season } \\
\text { (winter) } \\
\text { clo } \\
\end{array}$ & Activity & Category & $\begin{array}{c}\text { Operative } \\
\text { Cooling } \\
\text { season } \\
\text { (summer) } \\
{ }^{\circ} \mathrm{C}\end{array}$ & $\begin{array}{c}\text { Temperature } \\
\text { Heating } \\
\text { Season } \\
\text { (winter) } \\
{ }^{\circ} \mathrm{C} \\
\end{array}$ & $\begin{array}{c}\text { Mean Air } \\
\text { Cooling } \\
\text { season } \\
\text { (summer) } \\
\mathrm{m} / \mathrm{s} \\
\end{array}$ & $\begin{array}{c}\text { Velocity } \\
\text { Heating } \\
\text { season } \\
\mid \begin{array}{c}\text { (winter) } \\
\mathrm{m} / \mathrm{s}\end{array} \\
\end{array}$ \\
\hline \multirow[t]{3}{*}{ Office } & \multirow[t]{3}{*}{0.5} & \multirow[t]{3}{*}{1.0} & \multirow[t]{3}{*}{1.2} & A & $24.5 \pm 0.5$ & $22.0 \pm 1.0$ & 0.18 & 0.15 \\
\hline & & & & B & $24.5 \pm 1.5$ & $22.0 \pm 2.0$ & 0.22 & 0.18 \\
\hline & & & & C & $24.5 \pm 2.5$ & $22.0 \pm 3.0$ & 0.25 & 0.21 \\
\hline \multirow{3}{*}{\begin{tabular}{|l|} 
Cafeteria/ \\
Restaurant
\end{tabular}} & \multirow[t]{3}{*}{0.5} & \multirow[t]{3}{*}{1.0} & \multirow[t]{3}{*}{1.4} & A & $23.5 \pm 1.0$ & $20.0 \pm 1.0$ & 0.16 & 0.13 \\
\hline & & & & B & $23.5 \pm 2.0$ & $20.0 \pm 2.5$ & 0.20 & 0.16 \\
\hline & & & & $\mathrm{C}$ & $23.5 \pm 2.5$ & $20.0 \pm 3.5$ & 0.24 & 0.19 \\
\hline \multirow{3}{*}{$\begin{array}{l}\text { Department } \\
\text { Store }\end{array}$} & \multirow[t]{3}{*}{0.5} & \multirow[t]{3}{*}{1.0} & \multirow[t]{3}{*}{1.6} & A & $23.0 \pm 1.0$ & $19.0 \pm 1.5$ & 0.16 & 0.13 \\
\hline & & & & $\mathrm{B}$ & $23.0 \pm 2.0$ & $19.0 \pm 3.0$ & 0.20 & 0.15 \\
\hline & & & & C & $23.0 \pm 3.0$ & $19.0 \pm 4.0$ & 0.23 & 0.18 \\
\hline
\end{tabular}



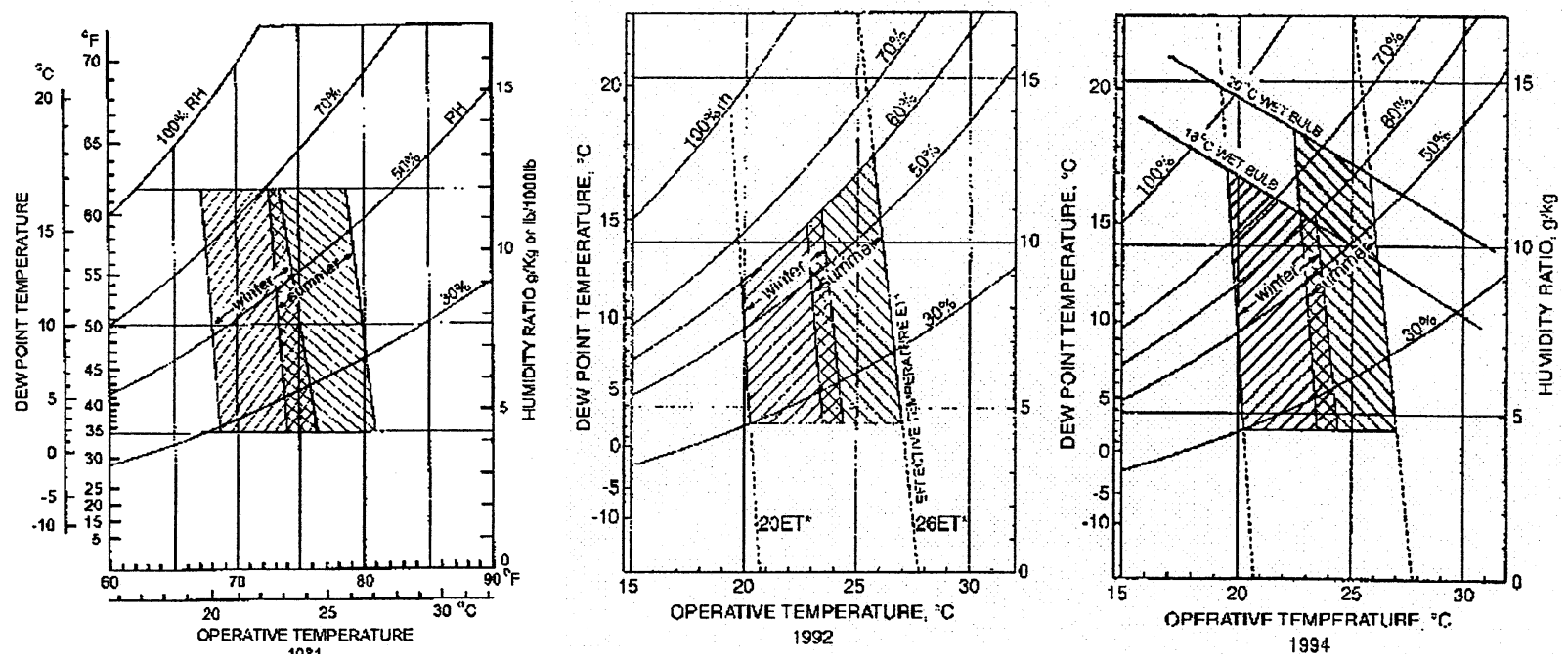

Fig. 1. History of ASHRAE Standard 55's acceptable ranges of operative temperature and humidity for people in typical summer and winter clothing during light and primarily sedentary activity ( $\leq 1.2 \mathrm{met})$. The ranges are based on a $10 \%$ dissatisfaction criterion.

sponding to the three classes of comfort, for three typical spaces. The optimal temperature is the same for all three classes but the acceptable range will change as the allowed percentage of dissatisfied changes. For the design of heating systems and heat load calculations, the lower value in the range should be used, and for cooling, the upper value is relevant.

The recommendations in ASHRAE Standard 5592 are mainly given for occupants performing light, primarily sedentary activity $(<1.2 \mathrm{met})$. The acceptable range of operative temperature is given in Fig. 1 for people in typical summer (cooling season) clothing $(\sim 0.5$ clo $)$ and typical winter (heating season) clothing $(\sim 1.0$ clo). Figure 1 shows the changes in the recommended ranges from 1981, 1992 and to the amendment in 1995. It is mainly the upper limit for humidity that has changed in subsequent revisions to the standard.

Separate comfort zones for two seasons reflect the fact that people usually change clothing according to outside temperature (summer-winter). It of course creates some problems in some work places that have a fixed dress code or in geographical regions that have very small seasonal variations in outdoor temperature. One of the problems with the current version of ASHRAE Standard 55 is that engineers use Fig. 1 uncritically, without necessarily confirming that the summer and winter clo levels match what is appropriate for the building they are designing or evaluating. While ASHRAE Standard 55-92 includes an analytical method to account for the effect of different clothing and activity levels, the incorporation of the PMV-PPD method in the revised standard will make this process much easier. Hopefully, this will result in engineers using more accurate estimates of clo values to determine the acceptable range of thermal conditions.

It is often discussed whether women and men have the same preference regarding temperature in a space. Most studies include the same number of female and male subjects; therefore it has been possible to show that, at the same activity and clothing insulation, women and men prefer the same temperatures. Also, regarding local comfort parameters, there is no difference between the sexes. In practice however, women and men working in the same space typically wear different levels of clothing insulation and this can influence their preference significantly. In an office setting, women tend to adapt their clothing more to the outside temperature, unlike men, who often wear the same suit all year round. This causes problems in summer where men may be dressed in 1 clo (business suit) and prefer a range $20-24^{\circ} \mathrm{C}$, while the women may be dressed in 0.5 clo (summer dress) and prefer a range $23-26^{\circ} \mathrm{C}$. An obvious compromise that is commonly adopted is to control temperature at $23-24^{\circ} \mathrm{C}$, but a better option (more comfortable with less energy use), is simply to allow men to dress lighter (summer pants, short-sleeved shirt). Similarly in winter, flexible dress codes should allow women to wear pants to work, instead of skirts or dresses.

For people with a low activity level (1-1.3 met) and average clothing $(\sim 0.7 \mathrm{clo})$, an increase in activity of 0.1 met can be compensated by an operative temperature decrease of $0.8^{\circ} \mathrm{C}$. An increase in clothing insulation with 0.1 clo can be compensated by an operative temperature decrease of $0.6^{\circ} \mathrm{C}$. At many workplaces, people may shift from seated to standing/walking, which on average corresponds to an activity increase of approx. 0.3 met. The preferred tem- 


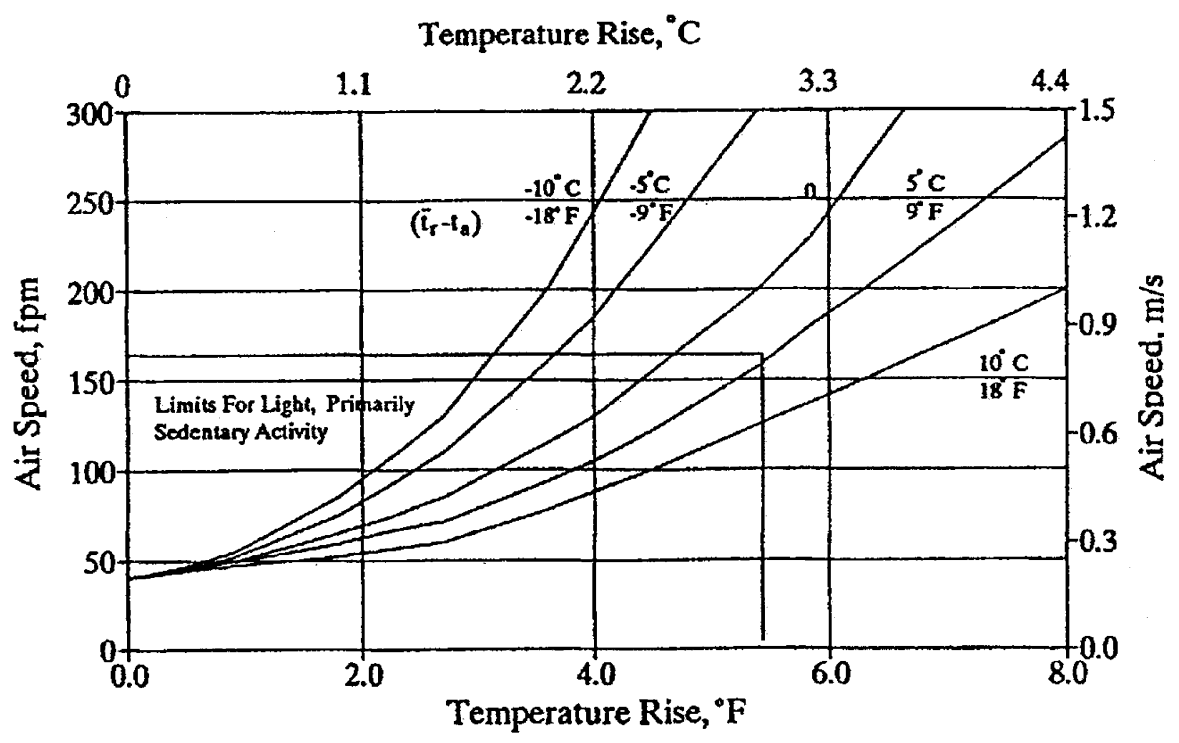

Fig. 2. Air speed required to offset increased temperature (reproduced from ASHRAE Standard 55-1992). The air speed increases in the amount necessary to maintain the same total heat transfer from the skin. This figure applies to increases in temperature above those allowed in the summer comfort zone with both $t_{r}$, and $t_{a}$ increasing equally. The starting point of the curves at $0.2 \mathrm{~m} / \mathrm{s}$ corresponds to the recommended air speed limit for the summer comfort zone at $26^{\circ} \mathrm{C}$ and typical ventilation (i.e., turbulence intensity between 30 and $60 \%$ ). Acceptance of the increased air speed requires occupant control of the local air speed.

perature decrease would then be $\sim 2.4^{\circ} \mathrm{C}$. As a chair for seated people will add an insulation of $0.1-0.15$ clo, the difference in activity will be partially compensated by the difference in chair insulation. If you stand up the insulation will decrease by $0.1-0.15$ clo, which corresponds to a preferred temperature change of $0.6-0.9^{\circ} \mathrm{C}$. This is less than half of what is needed to compensate for the increased activity. The example shows how effective clothing can be in compensating for individual differences in preference and activity level, and amplifies the point made earlier about allowing a flexible dress code so that people can use clothing modifications to adapt to existing thermal conditions and thus to maintain their individual comfort.

\section{Thermal Comfort Factors}

In the currently proposed revisions of ISO EN 7730 and ASHRAE-55-92, the influence and use of the following factors are being considered for inclusion.

\subsection{Increased air speed}

Standard 55-92 includes a diagram to estimate the air speed required to offset an increase in temperature (Fig. 2). The figure is based on a theoretical calculation, but an ASHRAE sponsored research project (843-RP, Human response to air movements, Part 1: Preference and draft discomfort) has recently verified the relation based on experimental tests with human subjects. This research project also investigated whether people achieved the same level of environmental acceptability at higher temperature/velocity combinations as they do at low temperature/velocity combinations. Toftum et al. (2000) experimentally verified the diagram in ASHRAE 55-92 (Fig. 2) for occupants having individual control (ceiling fans, operable windows). This study also showed that the requirement of personal control of the increased air speed is essential for this acceptance. In fact, a clear majority of subjects $(58 \%)$ preferred $28^{\circ} \mathrm{C}$ to $26^{\circ} \mathrm{C}$ (combined with $0.2 \mathrm{~m} / \mathrm{s}$ velocity) if they were allowed to select their own preferred air velocity in the warmer environment. Therefore, it may not be appropriate to offset a temperature increase by increasing the air speed within a centrally-controlled air system. In this case the requirements for draft (see later) have to be used. On the other hand, in commercial buildings that are primarily in cooling mode because of high internal loads, there may be an opportunity to reduce energy use whilst improving comfort. This can be achieved by allowing the temperature to rise slightly towards the higher end of the comfort zone, whilst giving people the opportunity to individually control air movement through either task/ambient conditioning systems, personal fans, or operable windows.

\subsection{Adaptation}

Several extensive field studies summarised by de Dear and Brager (1998) have shown that, in buildings running with centrally-controlled HVAC systems, the 


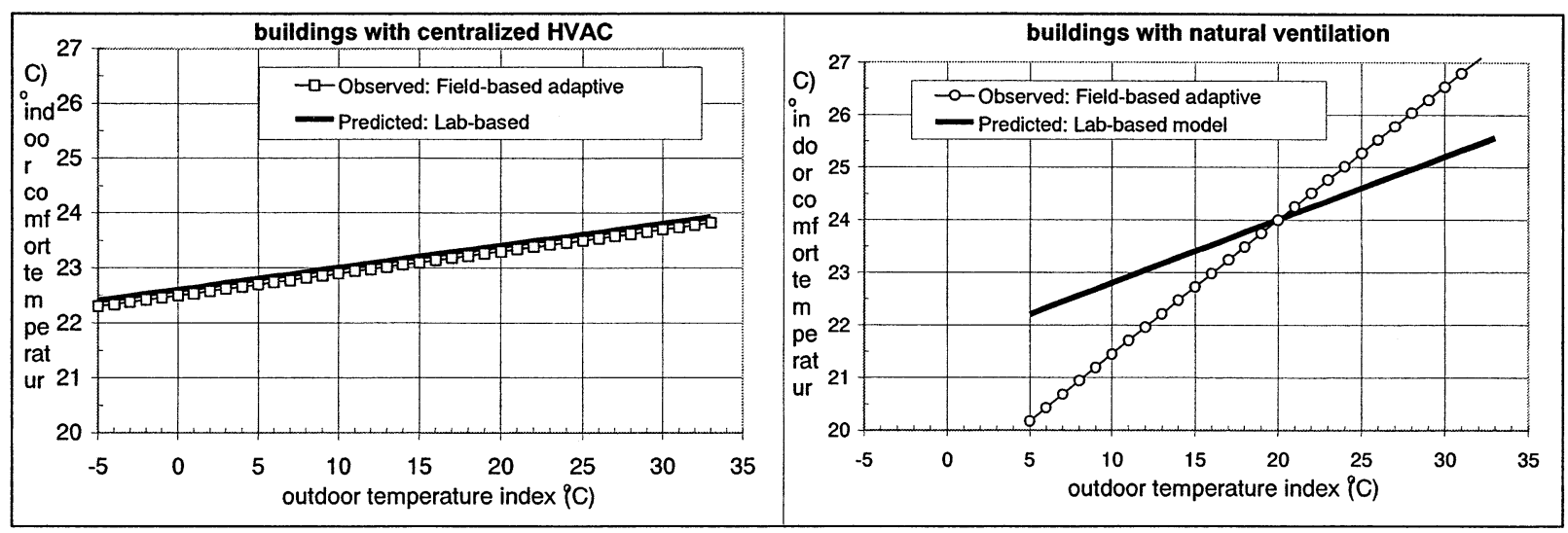

Fig. 3. Comparison of the RP-884 adaptive models' predicted indoor comfort temperatures with those predicted by the PMV model for both air-conditioned and naturally ventilated buildings (reproduced from de Dear and Brager, 1998).

PMV-model approximates the observed thermal comfort of occupants quite closely. Figure 3 shows a comparison between the optimum comfort temperatures observed in a database of building field experiments (de Dear and Brager, 1998) and the predicted optimum comfort temperatures in those same buildings based on building-averages of the six comfort parameters: $t_{a}, t_{r}, r h, v$, clo and met. The database consisted of 160 different buildings (mainly commercial offices) in which approximately 22,000 standardised comfort questionnaires were completed by occupants as their immediate workstation microclimate was monitored with the appropriate instrumentation. The buildings in the database were located in a wide cross-section of climate-zones across the globe, ranging from hot-dry desert conditions, through various temperate mid-latitude locations and extending to the tropics (de Dear, 1998).

As seen in the left-hand panel of Fig. 3, there is very close agreement between predicted and observed comfort temperatures in the database's centrally-controlled HVAC buildings and this holds true across a broad swathe of external climatic contexts (represented as mean monthly outdoor effective temperature). In centrally-controlled HVAC buildings the indoor climates were observed to be relatively static through time and the occupants can be considered to be in a steady-state relationship with those environments. Furthermore, the occupants of such buildings were typically excluded from the indoor climate control loop. We can therefore conclude that the humanenvironment system in such cases closely approximates the research design in the climate chamber comfort studies that provided the empirical inputs to the PMV model. The latter consisted of several hundred college-age subjects dressed in ensembles with fixed thermal insulation, sitting quietly in a climate chamber with fixed combinations of $t_{a}, t_{r}, r h, v$, for a couple of hours. In such climate chamber studies, re- searchers have found a fixed thermal environmental stimulus leads to a well-defined thermal sensation response.

The right-hand panel of Fig. 3 shows a comparison between PMV-based predictions of optimum thermal comfort and the actual comfort temperatures observed in naturally ventilated (free running, no mechanical cooling) buildings. The simple stimulus-response model of the human-environment system discussed above in the context of centrally conditioned buildings does not seem so relevant to these naturally ventilated buildings. In such buildings the occupants seem capable of adapting to a much broader range of conditions and can accept higher indoor temperatures than predicted by the PMV-model. The gradient of the PMV model's predictions in the right-hand panel of Fig. 3 obviously reflects, in part, the behavioural aspect of thermal adaptation - namely adjustments to clothing insulation and air velocity. In free-running buildings located in warmer climates the occupants typically wear lighter clothing, and this in turn causes the comfort temperature predicted by the PMV model in those buildings to be elevated (as noted in Section 2.1 , about $0.6^{\circ} \mathrm{C}$ for each 0.1 clo of thermal insulation). The PMV model can also account for the impact of higher air velocities, created perhaps by operable windows or fans. But the range of PMV-predicted comfort temperatures is relatively constrained (about $3^{\circ} \mathrm{C}$ ) in the naturally ventilated buildings of Fig. 3. By comparison, the comfort temperatures actually observed in naturally ventilated buildings (RP884 adaptive model" in Fig. 3) show a much wider range (over $7^{\circ} \mathrm{C}$ ) for which there is no explanation in the PMV model's inputs. Possibly there is a psychological dimension to thermal adaptation as well-a context-specific expectation (de Dear and Brager, 1998). A building occupant's perception of the indoor climate in their building at a given point in time may be influenced by what he or she expects to find there. 


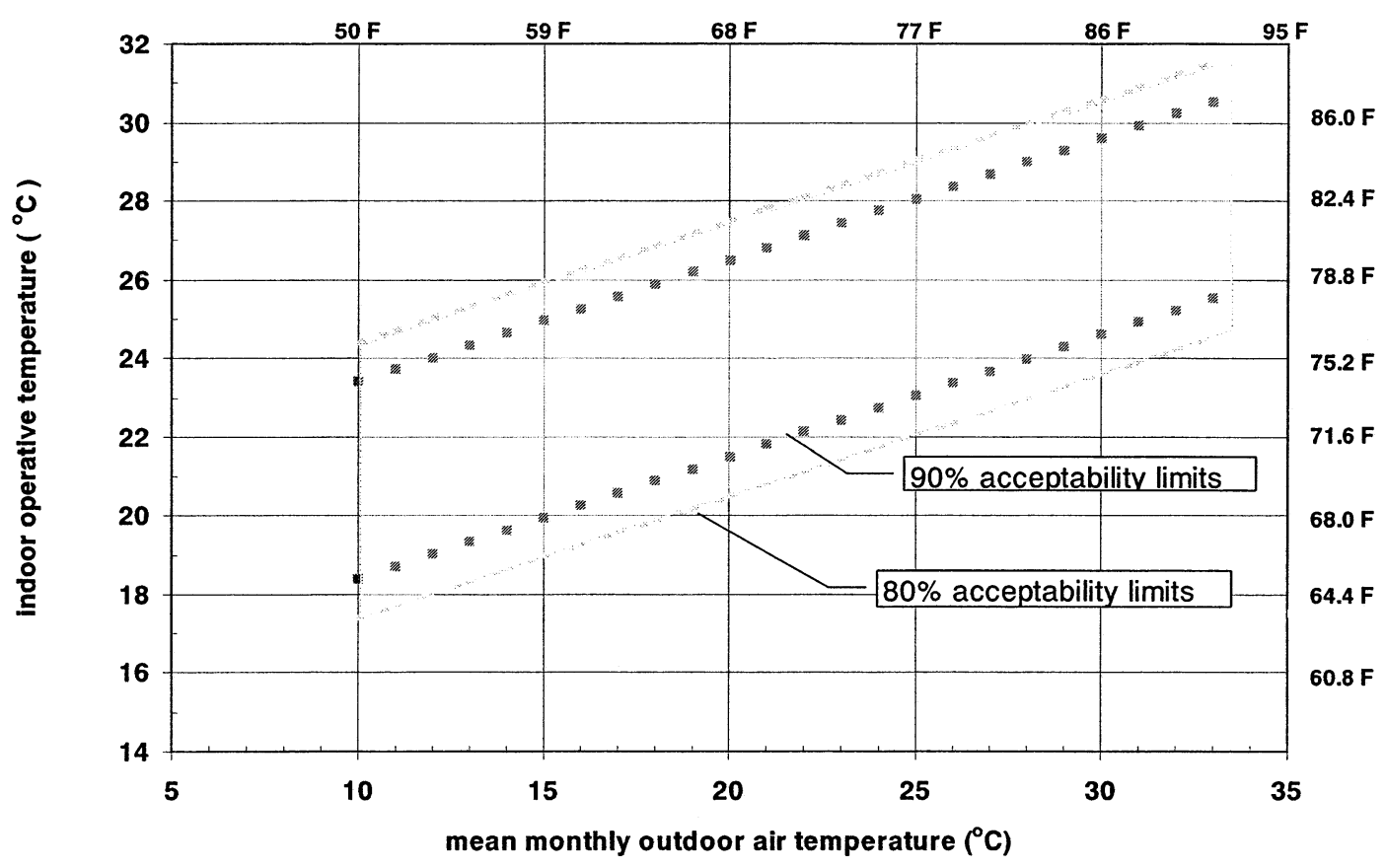

Fig. 4a. The Adaptive Comfort Standard (ACS) proposed for inclusion in the forthcoming revision to ASHRAE Standard 55. The option is restricted to naturally ventilated buildings in which conditions may be influenced by the occupants by primarily opening of windows to the outdoors. The $90 \%$ and $80 \%$ acceptability boundaries are $5^{\circ} \mathrm{C}$ and $7{ }^{\circ} \mathrm{C}$ wide respectively.

Probably the most significant source of these thermal expectations is the recent history of conditions actually experienced in the context in question. The human-environment system in this situation can therefore be regarded as a feedback loop in which the system's controlled variable, comfort temperature, drifts towards the running mean of thermal environments experienced both indoors and out.

In both the EN ISO 7730 and ASHRAE 55-92 revisions it is discussed how these results can be integrated into the standards. Figure 4 depicts the form of the Adaptive Comfort Standard (ACS) proposed for the forthcoming revision of Standard 55-92. The scope of the ACS option will be limited to naturally conditioned spaces in which thermal conditions of the space may be influenced by the occupants by primarily opening of windows. The space in question must be equipped with operable windows which open to the outdoors and which can be readily opened and adjusted by the occupants of the space. There must be no mechanical cooling system for the space (e.g. refrigerated air-conditioning, radiant cooling, or desiccant cooling). Mechanical ventilation with unconditioned air may be utilized, but opening and closing of windows must be the primary means of regulating conditions in the space. Although there was much debate as to whether the ACS should be applicable to hybrid (also called mixed-mode) buildings which combine both air-conditioning and natural ventilation, the currently proposed revisions to Standard 5592 will not allow these to be included in the ACS scope. The space may be provided with a heating system, but this ACS method does not apply when the heating system is in operation. The occupants of the space where the optional adaptive model may be applied, should be engaged in near sedentary physical activities with metabolic rates ranging from 1.0 met to 1.3 met.

As indicated above, there are some hypotheses as to why people accept higher temperatures in one type of building but not in another, and it is fair to say that, to date, there is no single explanation that has been universally accepted within the thermal comfort research community. Further research on this topic, particularly in relation to the comfort and behaviour of occupants of buildings with operable windows, is being initiated by ASHRAE.

Finally we note that even as far back as 1936, ASHRAE took into account thermal adaptation when specifying requirements for the indoor temperature. The following text can be found in ASHRAE Handbook 1936, Chapter 3:

"It should be kept in mind that southern people, with their more sluggish heat production and lack of adaptability, will demand a comfort zone several degrees higher than those given here for the more active people of northern climates"

\subsection{Personal control}

Only by personal control is it possible to compensate for inter- and intra-individual differences in pref- 
Table 3. Thermal insulation for garments and changes of the optimum operative temperature necessary to maintain a thermal sensation at neutral when various pieces of garments are added (or removed) at light, mainly sedentary, activity (1.2 met) (ISO 9920, 1992).

\begin{tabular}{|l|c|c|}
\hline Garment Description & $\begin{array}{c}\text { Thermal Insulation } \\
\text { clo }\end{array}$ & $\begin{array}{c}\text { Change of Operative Temp. } \\
\text { K }\end{array}$ \\
\hline Panties & 0.03 & 0.2 \\
T-shirt & 0.09 & 0.6 \\
Short sleeves shirt & 0.15 & 0.9 \\
Normal shirt, long sleeves & 0.25 & 1.6 \\
Shorts & 0.06 & 0.4 \\
Normal trousers & 0.25 & 1.6 \\
Light skirts (summer) & 0.15 & 0.9 \\
Heavy skirt (winter) & 0.25 & 1.6 \\
Thin sweater & 0.20 & 1.3 \\
Light. summer jacket & 0.25 & 1.6 \\
Normal jacket & 0.35 & 2.2 \\
\hline
\end{tabular}

erence and to thus increase the level of acceptance. The committees revising the ISO and ASHRAE standards are also discussing how this should be taken into account in existing standards and by design of HVAC systems. One way of having personal control is by changing clothing. Table 3 shows the effect of changing different garments. There is a need for further research related to the benefits of personal control of environmental conditioning systems. The market is seeing an increasing number of new workplacebased HVAC products that provide occupants with the ability to individually control of air flow, air temperature and/or radiation are also on the market (Bauman et al., 1993, 1995). To optimize the design and operation of such systems, it is important to know more than we currently do about the individual differences among occupants.

\subsection{Humidity}

As mentioned earlier, the recommended humidity limits have caused a lot of discussion during each revision of Standard 55. The influence of humidity on preferred ambient temperature within the comfort range is relatively small in Fig. 1 (EN ISO 7730, ASHRAE 55-92). In EN ISO 7730, a humidity range of $30-70 \% \mathrm{RH}$ is recommended, but mainly for indoor air quality reasons. In ASHRAE 55-92 the lower limit is a dew point temperature of $2^{\circ} \mathrm{C}$ and the upper limit at $18^{\circ} \mathrm{C}$ (winter) or $20^{\circ} \mathrm{C}$ (summer) wet bulb temperature. Requirements for acceptable indoor air quality (Berglund, 1998; Fang et al., 1996) will, however, specify a more narrow range for the humidity. But should this be taken into account in a thermal comfort standard? ASHRAE Standard 62-99 is recommending a $60 \%$ RH limit. In the revision of 55-92 there seems to be a general agreement among committee members to return to the upper limit used in 1981, namely a humidity ratio $12 \mathrm{~g} / \mathrm{kg}$ (Fig. 1) and no lower limit.

\section{Long Term Evalution of the General Thermal Comfort Conditions}

If criteria have to be met $100 \%$ of the time of occupancy, including under extreme weather conditions, the amount of heating and/or cooling capacity of any HVAC installation would be prohibitive. Economic and/or environmental considerations lead to a more pragmatic position of allowing the thermal conditions to exceed the recommended ranges for a limited time.

By computer simulation, comfort conditions are often tested over longer periods of time, for different types of buildings and/or HVAC design. There is a need to quantify with some index the long-term comfort conditions so that we may compare alternative designs. For these purposes, we recommend the following method for consideration in future revisions of the standards.

The time during which the actual PMV exceeds the comfort boundaries is weighed with a factor that is a function of the PPD. Starting from a PMV-distribution on a yearly basis, and the relation between PMV and PPD, the following is calculated:

$$
\text { Weighing factor } \quad w f=\frac{\mathrm{PPD}_{\text {actual PMV }}}{\mathrm{PPD}_{\mathrm{PMV} \text { limit }}}
$$

The weighted time is totalled for a characteristic working period during one year.

$$
\begin{array}{ll}
\text { Warm period: } & \sum w f \times \text { time hours, } \\
& \text { where } \mathrm{PMV}>\mathrm{PMV}_{\text {limit }} \\
\text { Cold period: } \quad & \sum w f \times \text { time hours, } \\
& \text { where } \mathrm{PMV}<\mathrm{PMV}_{\text {limit }}
\end{array}
$$

Table 4 is showing this concept. The weighing factors based on temperature difference $w f\left({ }^{\circ} \mathrm{C}\right)$ and $\mathrm{PPD}, w f$ (PPD) is shown for a comfort range of $23-26^{\circ} \mathrm{C}$, cor- 
responding to sedentary work (1.2 met) and light summer clothing $(0.5 \mathrm{clo})$. For temperatures above or below the interval the number of hours will be multiplied with these factors. It is seen that using the PPD weighing factor will result in a higher number of hours.

The summation of the product "weighing factor $\times$ time" is called "weighted time" in hours. The values may be used for the evaluation of long-term comfort conditions. An acceptable weighing time like 100 to 150 hours may be specified.

\subsection{Non-steady state thermal environments}

Non-steady state conditions often occur in the form of temperature cycles, temperature ramps and temperature transients. Some requirements are listed in ASHRAE Standard 55-92, but only limited research has been done on this subject to date. In many buildings there may be large energy savings if the indoor temperature is permitted to float (ramp) during a day. But what is still acceptable and what the impact is on productivity, remain largely unanswered questions in the thermal comfort literature to date. It is also unclear whether people's acceptance of nonsteady state conditions is influenced by whether they have personal control over those conditions, such as with a task-ambient control system, or with operable windows. An ASHRAE research project, 1161-TRP (Brager 2000), has just begun to examine this very issue by conducting field studies of office buildings with operable windows. Perhaps the findings of this research may eventually be incorporated into future

Table 4. Weighting factors based on temperature difference or PPD.

\begin{tabular}{|c|c|c|c|}
\hline \multicolumn{2}{|c|}{$\begin{array}{c}\text { Temperature } \\
{ }^{\circ} \mathrm{C}\end{array}$} & \multicolumn{2}{c|}{ Weighing factors } \\
\cline { 3 - 4 } Cool & 20 & wf $\left({ }^{\circ} \mathrm{C}\right)$ & wf(PPD $)$ \\
\hline \multirow{5}{*}{ Neutral } & 21 & 2 & 4,7 \\
& 22 & 1 & 3,1 \\
& 23 & 0 & 1,9 \\
\hline \multirow{4}{*}{ Warm } & 24 & 0 & 0 \\
& 25 & 0 & 0 \\
& 26 & 0 & 0 \\
& 27 & 1 & 0 \\
\hline & 28 & 2 & 1,9 \\
& 29 & 3 & 3,1 \\
\hline
\end{tabular}

revisions of the standards.

\section{Local Thermal Discomfort}

The PMV and PPD indices express warm and cold discomfort for the body as a whole. But thermal dissatisfaction may also be caused by unwanted cooling (or heating) of one particular part of the body (local discomfort). Local thermal discomfort may be caused by draught, high vertical temperature difference between head and ankles, too warm or too cool a floor, or by too high a radiant temperature asymmetry. Persons engaged in light sedentary activity are the most sensitive to local discomfort. The diagrams (Figs. 4-7) and Table 4 apply to this group of people with a thermal sensation for the whole body close to neutral. At higher activities, people are less thermally sensitive and consequently the risk of local discomfort is lower. The local discomfort criteria based on the three classes in Table 1 are listed below in Table 5 for possible inclusion in the current round of revisions to the standards.

\subsection{Draught}

The influence of air velocity on general thermal comfort and on local thermal comfort has been studied quite extensively in the USA, Europe and Japan. The effect of air velocity has not only been studied with sedentary people in general thermal comfort; but also with people at higher activity levels and who are on the warm or cold side of comfort. Air motion within a space can lead to draught sensation, but may also lead to improved comfort under warm conditions. The draught model, which is included both in ASHRAE Standard 55 and ISO EN 7730, is listed below:

$$
D R=\left(\left(34-t_{a}\right) \cdot(v-0.05)^{0.62}\right) \cdot(0.37 \cdot v \cdot T u+3.14)
$$

where:

$D R \quad$ is the draught rating, i.e. the percentage of people dissatisfied due to draught;

$t_{a} \quad$ is the local air temperature in ${ }^{\circ} \mathrm{C}$;

$v \quad$ is the local mean air velocity in $\mathrm{m} / \mathrm{s}$; and

$T u$ is the local turbulence intensity in per cent.

The model of draught is based on studies comprising 150 subjects exposed to air temperatures of 20

Table 5. Recommended categories for local thermal discomfort parameters.

\begin{tabular}{|c|c|c|c|c|c|c|}
\hline \multirow{2}{*}{ Category } & Vertical air & Floor surface & \multicolumn{4}{|c|}{ Radiant temperature asymmetry } \\
& $\begin{array}{c}\text { temp. diff. } \\
\mathrm{K}\end{array}$ & $\begin{array}{c}\text { temperature } \\
{ }^{\circ} \mathrm{C}\end{array}$ & \multicolumn{4}{|c|}{$\mathrm{K}$} \\
\cline { 4 - 7 } & & & Warm & $\begin{array}{c}\text { Cool } \\
\text { ceiling }\end{array}$ & $\begin{array}{c}\text { Cool } \\
\text { wall }\end{array}$ & Warm wall \\
\hline $\mathrm{A}$ & $<2$ & $19-29$ & $<5$ & $<14$ & $<10$ & $<23$ \\
\hline $\mathrm{B}$ & $<3$ & $19-29$ & $<5$ & $<14$ & $<10$ & $<23$ \\
\hline $\mathrm{C}$ & $<4$ & $17-31$ & $<7$ & $<18$ & $<13$ & $<35$ \\
\hline
\end{tabular}



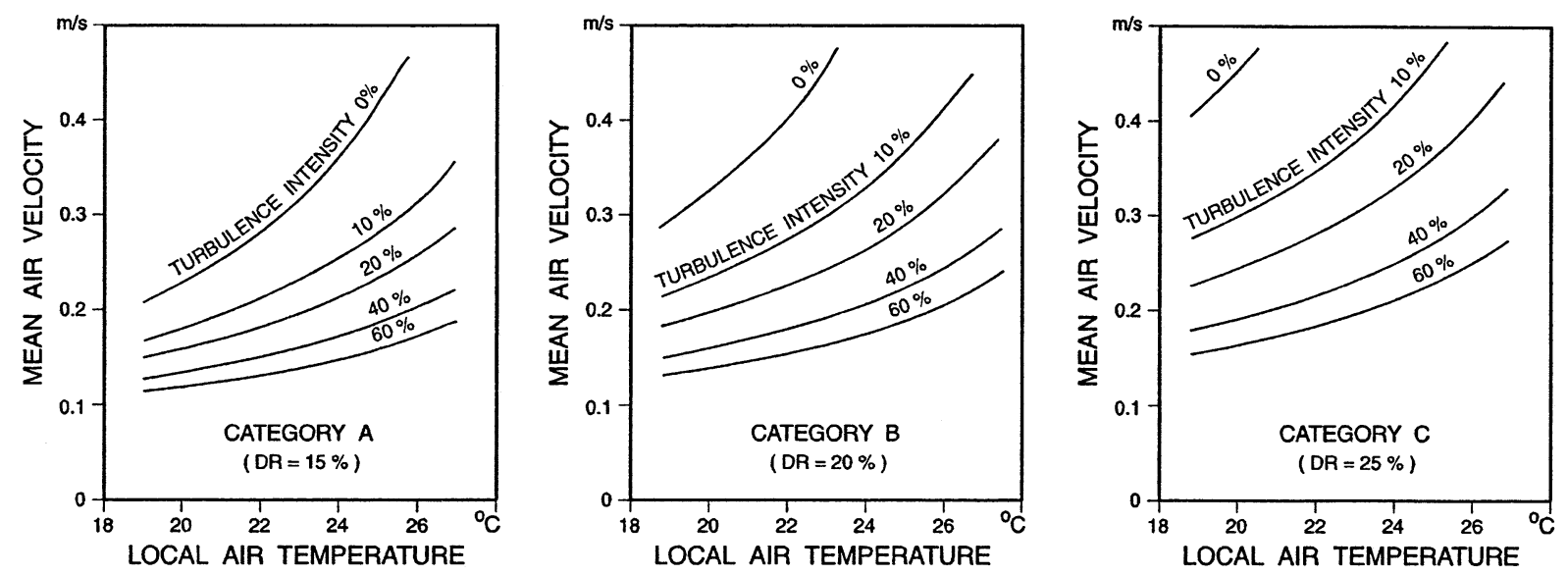

Fig. 4b. Mean air velocity as a function of local air temperature and turbulence intensity for the three categories of the thermal environment.

$26^{\circ} \mathrm{C}$, mean air velocities of $0.05-0.4 \mathrm{~m} / \mathrm{s}$ and turbulence intensities of $0-70 \%$. In mechanical ventilated spaces the turbulence intensity is typically $40-50 \%$. The model applies to people at light, mainly sedentary activity with a thermal sensation for the whole body close to neutral. The sensation of draught is lower at activities higher than sedentary, and for people feeling warmer than neutral.

Recent studies by Griefhahn (1999) indicate that this model must be modified to take into account length of exposure and activity level. Studies by Toftum et. al. (1996a, 1996b, 1997, 2000) show additional influence of the velocity directions. The two studies do not agree completely with the above draught model. According to Griefhahn the models predict DR percentages which are too low, while according to Toftum et al. it predicts values which are too high. Further studies are needed before the draught model and Fig. 4 from the proposed standards will be changed.

\subsection{Vertical air temperature difference}

A high vertical air temperature difference between head and ankles may cause discomfort. In Fig. 5, the percentage of those dissatisfied as a function of the vertical air temperature difference between head and ankles, is shown (1,1 and $0,1 \mathrm{~m}$ above the floor). The figure applies when the temperature increases upwards. People are less sensitive for decreasing temperature

The studies have mainly been made with seated people in general thermal comfort so there is a need to extend research to human subjects at other activity levels before revisions of the indoor thermal envrironment standards can be proposed. The criteria in Table 5 and Figure 5 will be included in the proposed revision.

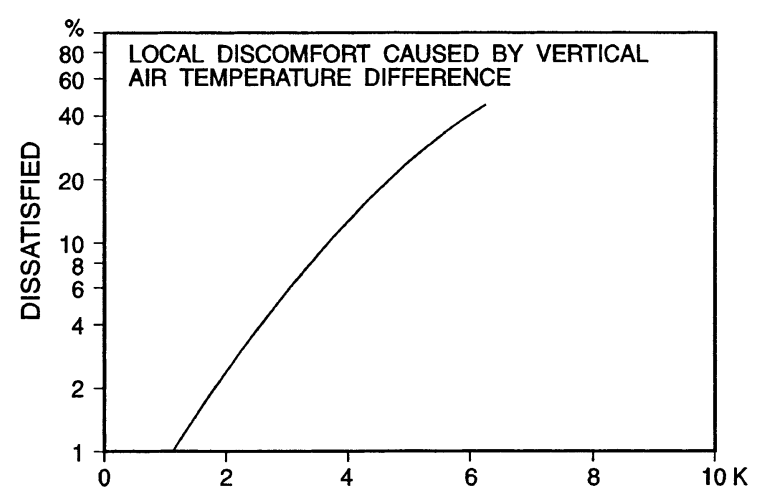

AIR TEMPERATURE DIFFERENCE BETWEEN HEAD AND FEET

Fig. 5. Local discomfort caused by vertical air temperature difference. Applies when the temperature increases with height from the floor.

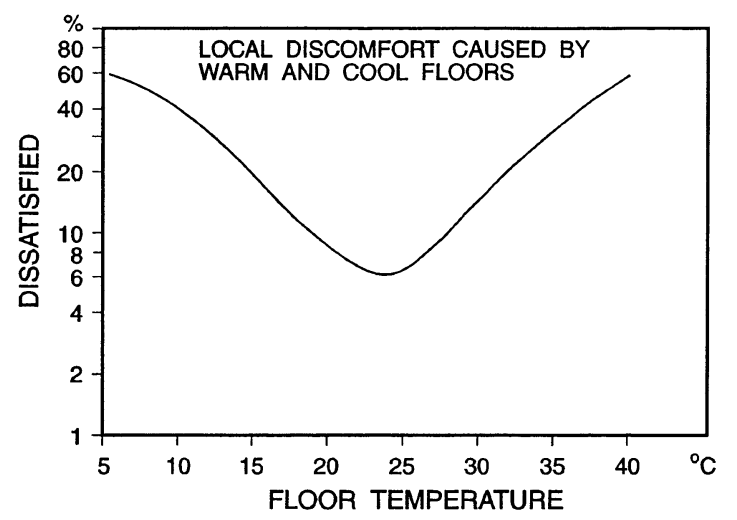

Fig. 6. Local thermal discomfort caused by warm or cold floors.

\subsection{Floor temperature}

If the floor is too warm or too cool, the occupants may feel uncomfortable due to warm or cool feet. For people wearing light indoor shoes, it is the temperature of the floor rather than the material of the floor covering which is important for comfort. In Fig. 6 the percentage of those dissatisfied as a function of the 
Table 6. Comfortable floor temperatures for standing people on typical floor constructions; sedentary people prefer temperatures $1-2^{\circ} \mathrm{C}$ higher.

\begin{tabular}{|c|c|c|c|c|c|c|}
\hline \multirow[t]{2}{*}{ Floor construction on concrete } & \multicolumn{2}{|c|}{$\begin{array}{l}\text { Heat loss to } \\
\text { foot measured } \\
\text { according to } \\
\text { DIN } 52614\end{array}$} & \multicolumn{2}{|c|}{$\begin{array}{l}\text { Optimum floor } \\
\text { temperature }\end{array}$} & \multicolumn{2}{|c|}{$\begin{array}{l}\text { Recommended floor } \\
\text { temperature range }{ }^{\circ} \mathrm{C}\end{array}$} \\
\hline & $1 \mathrm{~min}$. & $\begin{array}{c}10 \\
\mathrm{~min} . \\
\mathrm{kJ} / \mathrm{m}^{2}\end{array}$ & ${ }^{1} \mathrm{~min}$. & ${ }^{\circ} \mathrm{C}$ & $\begin{array}{c}1 \mathrm{~min} . \\
10 \% \\
\text { dissatisfied } \\
\end{array}$ & $\begin{array}{c}10 \mathrm{~min} . \\
15 \% \\
\text { dissatisfied }\end{array}$ \\
\hline Textile layer & 17 & 75 & 19 & 24 & $8-30$ & $20-28$ \\
\hline Wilton-carpet & 20 & 91 & 21 & 24.5 & $12-30.5$ & $21-28$ \\
\hline Sisal-carpet & 14 & 123 & 23 & 25 & $15.5-31$ & $22.5-28$ \\
\hline Needled felt sheet & 21 & 111 & 22 & 25 & $13-30.5$ & $22-28$ \\
\hline $5 \mathrm{~mm}$ cork & 26 & 145 & 24 & 26 & $17-31$ & $23-28$ \\
\hline Pinewood floor & 29 & 124 & 25 & 25 & $18.5-31$ & $22.5-28$ \\
\hline Oakwood floor & 36 & 182 & 26 & 26 & $21.5-31.5$ & $24.5-28$ \\
\hline Wooden floor & 38 & 134 & 26.5 & 25.5 & $22-31.5$ & $23-28$ \\
\hline Vinyl-asbestos tile & 80 & 485 & 30 & 28.5 & $28-32.3$ & $27.5-29$ \\
\hline PVC-sheet with felt underlay & 49 & 242 & 28 & 27 & $24.5-32$ & $25.5-28$ \\
\hline PVC-sheet (2 mm) & 60 & 365 & 29 & 27.5 & $26-32$ & $26.5-28.5$ \\
\hline $\begin{array}{l}5 \mathrm{~mm} \text { tessellated floor on gas } \\
\text { concrete }\end{array}$ & 60 & 301 & 29 & 27 & $26-32$ & $26-28.5$ \\
\hline $\begin{array}{l}5 \mathrm{~mm} \text { tessellated floor on } 20 \mathrm{~mm} \\
\text { cork }\end{array}$ & 63 & 211 & 29 & 26.5 & $26.5-32$ & $25-28$ \\
\hline $2.5 \mathrm{~mm}$ hard linoleum on wood & 46 & 176 & 28 & 26 & $24-32$ & $24-28$ \\
\hline $2.2 \mathrm{~mm}$ hard linoleum on concrete & 45 & 296 & 28 & 27 & $23.5-32$ & $26-28.5$ \\
\hline Painted concrete floor & 77 & 487 & 30 & 28.5 & $27.5-32.5$ & $27.5-29$ \\
\hline Concrete floor & 50 & 298 & 28.5 & 27 & $24.6-32.0$ & $26-28.5$ \\
\hline Marble & 75 & 511 & 30 & 29 & $27.5-32.5$ & $28-29.5$ \\
\hline $\begin{array}{l}\text { Concrete slab finished with steel } \\
\text { trowel }\end{array}$ & 63 & 475 & 29 & 28.5 & $26.5-32$ & $27.5-29$ \\
\hline $\begin{array}{l}\text { Concrete slab finished with } \\
\text { wooden float }\end{array}$ & 60 & 419 & 29 & 28 & $26.0-32$ & $27-29$ \\
\hline
\end{tabular}

floor temperature, is shown [for spaces which people are with bare feet please see ISO/CD13732-2. In this case not only the floor temperature but also the floor material is important for comfort (Table 6)].

The studies on floor temperatures and comfort have been made for the situation where only the feet are in contact with the floor. In Asia it is common to sit or lie on the floor. This may have an effect on the preferred floor temperature. Several studies have been made in Japan and Korea, but often with a very limited number of subjects. It is also very important to distinguish between electrically heated floors and water-based floor heating systems. When the heat output is blocked by contact with body parts (feet) or furniture, the heat output from a water based system will decrease with the decreasing temperature difference between surface and water. An electrically heated floor will keep supplying the same amount of heat, which may result in too high surface temperatures. This has not been taken into account in the Table 5 proposed for the revision of ISO EN7730 and ASHRAE 55.

\subsection{Radiant asymmetry}

Radiant asymmetry (difference in radiation from too opposite half-rooms) may also cause discomfort. People are most sensitive to radiant asymmetry caused by warm ceilings or cool walls (windows). In Fig. 7, the percentage of those dissatisfied as a function of the radiant temperature asymmetry caused by a warm ceiling, a cool wall, a cool ceiling or by a warm wall, is shown. Radiant asymmetry is rarely a problem in ventilated/air-conditioned spaces, except at high illumination levels and at large window areas. Direct solar radiation should be avoided in the occupied zone, by means of building design or solar shading devices.

In industrial work places, it is mainly the radiant asymmetry from overhead radiant heaters or a hot roof, which cause problems. The values established for sedentary persons are too conservative for the higher activity levels and higher ceilings in industry. A study by Langkilde et al. (1985) shows that significantly higher radiant asymmetry is acceptable. Based on criteria similar to the above requirements of less 


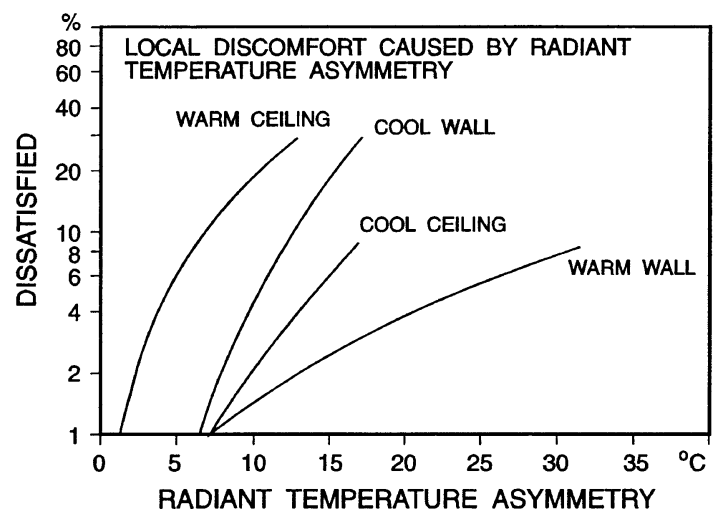

Fig. 7. Local thermal discomfort caused by radiant temperature asymmetry.

than $5 \%$ dissatisfied, the recommended asymmetry limit is $10-14^{\circ} \mathrm{C}$. In these studies there were no differences between seated and standing persons. Also the influence of wearing a helmet was insignificant. In previous studies simulating the conditions in residential and commercial buildings, the distance between the heated ceiling and the head of the subjects was only $1 \mathrm{~m}$. While the distance between the infrared radiant heaters and the head was $4 \mathrm{~m}$ in the experiments reported by Langkilde et al. (1985). For the same asymmetry level in the two types of experiments, the difference in the radiant temperature level at feet and head height will be much larger when the distance from the person to the heaters is small $(1 \mathrm{~m})$. In industrial work places where the heaters normally are mounted more than $4 \mathrm{~m}$ from the occupants, a larger asymmetry can be accepted before the temperature difference felt between head and feet causes discomfort. That is also the reason why no difference was found between seated and standing persons. The change proposed for the standards is inclusion of Table 5 with the three levels and Figure 7.

\section{Combined Effects}

There is very little information on the combined effect of general thermal comfort and local thermal comfort. Some studies have been made on the influence of air velocity (draught) and general thermal discomfort. The influence of the general thermal comfort on other local discomfort parameters like radiant temperature asymmetry, vertical air temperature differences and floor temperatures has not been studied. Moreover, very few studies have looked at the combined effect of several local thermal discomfort parameters. In this area there is a need for research before it will be possible to predict the total number of those dissatisfied in a space.

\section{Discuccion and Conclusion}

Some important issues are being discussed in the current round of standard revisions. Fulfilling the given criteria does not guarantee $100 \%$ thermal acceptability. Due to individual differences, it may be very difficult to satisfy everybody in a space but some forms of individual control of the thermal environment combined with individual adaptation (clothing, activity) will increase the level of acceptance.

The above criteria show that some restrictive requirements on air velocity are necessary to avoid the sensation of draught in cool environments. In warm environments it may, however, be beneficial for the total comfort to increase the air velocity above these levels. This effect is partly included in the use of the PMV-index. New studies indicate that, if the occupant is allowed to select their own air speed, there is a clear preference for warm temperatures $\left(28^{\circ} \mathrm{C}\right) \mathrm{com}$ pared to moderate temperatures and low, fixed air speeds $\left(26^{\circ} \mathrm{C}\right.$ and $\left.0.2 \mathrm{~m} / \mathrm{s}\right)$ (Toftum et al., 2000).

Field studies have shown that for heated and air conditioned buildings the use of the PMV-PPD index agrees with the observations. But for "free running" buildings in warm climates, where summertime reliance on natural ventilation occurs, there seems to be an additional adaptation which cannot be explained alone by behavioural adaptations, such as changes to clothing or air velocity. It may be due partly to the adaptation of the activity (metabolic rates), which is very difficult to measure in the field. Most likely, it is primarily due to psychological adaptation in the form of shifting expectations, which result from having personal control, and a history of more diverse thermal experiences.

Another issue is whether the thermal environment must be inside the given range $100 \%$ of the time, or whether it is more reasonable to allow conditions to vary outside the specified criteria for some limited periods of time. For each of the thermal comfort factors it may be possible from measurements or calculations to calculate a factor " $\%$-dissatisfied $\times$ time" to take into account how long a time, and by how much, the conditions may deviate from the established comfort criteria. For such factor(s), additional criteria may be established or the values should be given in terms of an overall index of indoor environmental quality.

Except for draught (air velocity) the local thermal discomfort parameters like vertical air temperature differences, floor surface temperatures and radiant temperature asymmetry have mainly been studied for younger, sedentary people in general thermal comfort. The studies have in most cases only looked at one factor. There is a need to extend the study on local thermal comfort parameters for other types of 
activities and subject groups.

To be able to predict the combined influence of the thermal environment on people, it is also important to obtain more information on the combined effect of general and local comfort and when there is exposure to several local discomfort parameters at the same time. As there are very large inter-individual variances in response to the thermal environment, it is essential to use relatively large samples of subjects to enable research results to achieve the statistical significance necessary for generalisation in practice.

A key objective of standards is to transfer the latest scientific knowledge into practice. Standards governing indoor thermal environments at the international level (ISO-International Standard Organisation), (CEN-European Standard Organisation), and also the national level (ASHRAE-American Society of Heating, Refrigerating and Air Conditioning Engineers) are on a constant cycle of revision, public review, and promulgation. Substantial progress in our understanding of human response to thermal environments has been made in numerous laboratory and field research projects in the last decade. Many of these significant advances are now informing the current round of standard revisions.

\section{References}

ASHRAE Standard 55-1992. Thermal environment conditions for human occupancy. ASHRAE, Atlanta.

ISO EN 7730, 1994. Moderate thermal environments-Determination of the PMV and PPD indices and specification of the conditions for thermal comfort. International Standards Organization. Geneva.

Bauman, F. S., Arens, E. A., Tanabe, S., Zhang, H., Baharlo, A. (1995) Testing and optimizing the performance of a floor-based task conditioning system. Energy and Buildings. V.22(3), pp. 173-86.

Bauman, F. S., Zhang, H., Arens, E. A., Benton, C. C. (1993) Localized comfort control with a desktop task conditioning system: Laboratory and field measurements. ASHRAE Transactions. V.99(2), pp.733-749.

Berglund, L. G., 1998. "Comfort and Humidity." ASHRAE Journal, V.40(8).

Brager, S. G, 2000. "1161-TRP: The effect of personal control and thermal variability on comfort and acceptabil- ity", contract awarded by ASHRAE, September 2000.

Brager, G. S. and R. de Dear. 2000. "A standard for natural ventilation.” ASHRAE Journal. V.42(10), pp. 21-27.

CR 1752, 1998. Ventilation for Buildings: Design Criteria for the Indoor Environment. CEN, Brussels.

de Dear, R. and Brager, G. S., 1998. Developing an adaptive model of thermal comfort and preference. ASHRAE Trans., V.104 (1a), pp. 145-167.

Fang, L., Clausen, G. and Fanger, P. O., 1996. The impact of temperature and humidity on perception and emission of indoor air pollutants. Proceedings of Indoor Air '96, Tokyo, Institute of Public Health.

Fanger, P. O., Ipsen, B. M., Langkilde, G., Olesen, B. W., Christensen, N. K. and Tanabe, S. 1985. Comfort limits for asymmetric thermal radiation. Energy and Buildings. V.8, 225-226.

Fanger, P. O., Melikov, A. K., Hanzawa, H. and Ring, J. 1988. Air Turbulence and sensation of draft. Energy and Buildings. 12(1).

Griefhahn, B., 1999. Bewertung von Zugluft am Arbeitsplatz. Fb 828, Schriftenreihe der Bundesanstalt für Arbeitsschutz und Arbeitsmedizin, Dortmund.

ISO EN 9920, 1992. Ergonomics-Estimation of the thermal insulation and evaporative resistance of a clothing ensemble. International Organization for Standardisation, Geneva.

ISO EN 7730, 1994. Moderate thermal environments-Determination of the PMV and PPD indices and specification of the conditions for thermal comfort. International Standards Organization. Geneva.

Langkilde, G., Gunnarsen, L. and Mortensen, N. 1985. "Comfort limits during infrared radiant heating of industrial spaces," Proceedings of CLIMA 2000, Copenhagen.

Toftum, J., Nielsen, R., 1996a. Draught sensitivity is influenced by general thermal sensation. International Journal of Industrial Ergonomics, 18(4), 295-305.

Toftum, J., Nielsen, R., 1996b. Impact of metabolic rate on human response to air movements during work in cool environments. International Journal of Industrial Ergonomics, 18(4), 307-316.

Toftum, J., Zhou, G., Melikov, A., 1997. Airflow direction and human sensitivity to draught. Proceedings of CLIMA 2000, Brussels.

Toftum, J., Melikov, A. K., Rasmussen, L. W., Kuciel, A. A., Cinalska, E. A., Tynel, A., Bruzda, M., and Fanger, P. O. 2000: Human response to air movement. Part 1: Preference and draught discomfort. ASHRAE Project 843$T R P$, Technical University of Denmark (in press). 